\title{
TAPPING INTO OPPORTUNITY BEYOND SOUTH AFRICA FOR SMALL BUSINESS EXPANSION ${ }^{1}$
}

\author{
The opportunity is often lost by deliberating - Publilius Syrus
}

Masana Twala and Emily Brown, the co-founders of ME Data Services (MEDS), believed they had identified an excellent opportunity in the Business Process Outsourcing (BPO) domain. They were excited to set their idea in motion and, as many technology services entrepreneurs do, they feared that if they did not act promptly they could lose this chance. However, as recent entrants to the fiercely competitive BPO) industry in South Africa, pausing to map out the future of their new company was a necessity rather than a luxury.

The BPO sector in South Africa offering IT enabled data management services including: data capturing, data conversion, data analysis and data cleansing. MEDS was a new entrant to the BPO industry. Nevertheless, the company had managed to secure few local clients in the highly competitive BPO domain. The organisation now wished to expand. Specifically, the founders were looking to secure business from clients in other locations such as the UK, US and Europe.

The two entrepreneurs had identified various challenges both internally in MEDS and externally in the BPO sector that they had to overcome if their new company was to flourish. The obstacles were complex and touched on all facets of the organisation. Of prime concern internally were issues regarding human resources, technology and other resources, processes and organisational culture. Externally, they sought to understand the political, economic, social and technological factors operating in their environment. Masana and Emily knew that as a start-up the first few years would be turbulent - to say the least—and as such they were determined to compile a strategy that would guide them over the next 5 years. The pair had several issues to consider before making their next move. They needed to take into account the various internal and external constraints in order to map out a strategy for their new business in the fast paced BPO domain. How should their 5-10 year plan look like?

\footnotetext{
${ }^{1}$ Copyright (C) 2018, Tendani Mawela. This case was prepared for the purpose of class discussion. Names and some information have been disguised. This case is published under a Creative Commons BY-NC license and originally appeared as a chapter in Transforming Society Using ICT: Contemporary Discussion Cases from Africa. Permission is granted to copy and distribute this case for non-commercial purposes, in both printed and electronic formats.
} 


\section{South Africa Background}

South Africa, a popular tourist destination, was a developing country on the southernmost tip of the African continent with an estimated population of 56.5 million people (STATS-SA, 2017a). The country's land area was 1,219,090 sq. km and the neighbouring countries included Namibia, Zimbabwe, Botswana, Mozambique and Swaziland. Also, the country fully surrounded the Kingdom of Lesotho. South Africa was a diverse nation comprising of a multitude of cultures, languages and religious beliefs. The country's economy could be considered a middle-income emerging market with a supply of natural resources including diamonds, platinum and gold. Unlike many countries in sub-Saharan Africa, South Africa had a mature and structured financial, legal, communications, energy and transport sectors. Additionally, its stock exchange (Johannesburg Stock Exchange) was considered Africa's largest and among the top twenty globally. The nominal GDP figures stood at R1 145 billion for the second quarter of 2017 (see Exhibit 1). The country faced various challenges including high unemployment rate, poverty and inequality. Statistics South Africa reported that "more than one out of every two South Africans were poor in 2015, with poverty headcount increasing to 55.5\% from a low of 53.2\% in 2011" (STATS-SA, 2017b, c). The literacy rates indicated that $94 \%$ of people above the age of 15 were able to read and write.

\section{Business Process Outsourcing (BPO)}

BPO involved an organisation contracting an external provider to manage and deliver IT intensive business processes based on specific performance criteria (Yang et al., 2007). According to a Gartner Inc. (NYSE: IT) (2016a) report, the BPO industry had over 6.7 million skilled workers exporting IT and business process skills. Gartner Inc. (NYSE: IT) (2016b) further identified three major BPO markets by geographical location. The Asia /Pacific market was one of the oldest and offered the largest pool of human resources coupled with the lowest cost structure and highly skilled talent. In the European Middle East and Africa (EMEA) region, companies were growing their export services by approximately $10 \%$ 15\% per year (Gartner, 2016b). The European BPO providers offered additional languages such as French and German, in contrast to the Asia/Pacific companies, and were therefore capturing at competitive rates an increasing portion of the European market in conjunction with convenient time zones, cultural familiarity and technical skills. Lastly, the Americas region was also showing promising growth. This region was important for several groups of clients such as American buyers, large multinationals (especially those with Latin American operations) and large organizations that had headquarters in Latin America but also had large business operations in North America. Clients that sought outsourcing services from the Americas region were generally driven by the following:

- $\quad$ The need to balance risk in their outsourcing strategy;

- $\quad$ Complex business needs that require a higher cultural affinity from their BPO service provider;

- $\quad$ Requirements for real time information exchange and thus a need for similar time zones;

- $\quad$ A requirement for specifically Spanish speaking resources; and

- $\quad$ Access to competitive human resources.

Some of the benefits that companies could enjoy from following a BPO strategy included:

- $\quad$ The potential to become more nimble and thus adjust to customers' new requirements within a shorter time period;

- $\quad$ Better use and optimization of scarce resources;

- $\quad$ Access to efficient and skilled human resources that could contribute to cost savings;

- $\quad$ Costs savings may also be experienced through process improvements and the adoption of new technologies; 
- $\quad$ Productivity improvements;

- Improved focus on strategic activities, as non-core activities were outsourced to a BPO service provider.

There were, however, several risks that organizations often faced in following the outsourcing route:

- Data security risks, since confidential organizational information was handed to a BPO supplier;

- $\quad$ Hidden upfront costs that were not always obvious;

- $\quad$ Provider risks, that included poor quality and compromised turnaround times;

- $\quad$ Loss of control, often resulting from the difficulty in managing an offshore provider.

Looking ahead, the global BPO industry was said to be facing the several disruptive trends that might impact on future operations of BPO companies. These included the following, as highlighted by Sharma (2016):

- $\quad$ Clients wanted BPO service providers with specialised skills;

- $\quad$ Technology changes, such as the Internet of Things, Social Media and Big Data, were adding alternative service opportunities for BPO companies;

- $\quad$ Geographical markets, previously lagging in adopting BPO, were opening up to the potential benefits of outsourcing;

- $\quad$ Opportunities to scale-up services for existing BPO clients who needed to further transform their organisations in response to changes in their industries.

\section{South African Business Process Outsourcing Industry}

Historically, the global BPO industry had been dominated by companies from India and the Philippines. In recent years, however, companies were looking beyond these two BPO havens and South Africa had emerged as a viable option. In 2012, South Africa had been acknowledged as the Offshoring Destination of the Year by the UK National Outsourcing Association. Additionally, other than being shortlisted for the European Outsourcing Association's (EOA) Offshoring Destination of the Year Award in 2013 (Gartner Inc. (NYSE: IT), 2016b), South Africa had been categorised as a "primary location” for BPO services. In basic terms, this meant that South Africa was a country that enjoyed high interest from enterprise buyers and had attractive BPO services options based on overall value, cost and risk. It was estimated that the country's offshore BPO sector had employed 10,000 FTE's (full-time equivalents) in 2010 which grew to 17,000 FTE's by 2013 (BPESA, 2015). According to an industry report, South Africa was also noted as an emerging and pioneering BPO location (Cushman \& Wakefield LLP, 2016)

Various factors were cited for contributing to the increasing growth of the BPO industry. South Africa had identified BPO as a strategic enabler for economic and social growth. South Africa also had a supportive government for the BPO drive. The government had implemented the Business Process Services (BPS) incentive programme from January 2011 with the objectives of attracting investment and creating employment opportunities in South Africa through offshoring activities. Since the programme's inception, the incentive has resulted in the creation of about 9077 new jobs with an average growth rate of 26\% per annum during the period 2011-2014 (DTI, 2015).

South Africa also had a mature domestic market underpinned by strong legal and financial services domains. Notwithstanding the infrastructure challenges, there were areas of progress such as the doubling 
of undersea cables and reduction in telecommunication costs. South Africa offered cost savings of as much as $50 \%$ when compared to the source market of potential clients from the UK and USA. The bulk of the offshore BPO services offered in South Africa included voice, at $80 \%$ of market share (contact centres), followed by back office services (12\%) and knowledge process outsourcing (8\%).

\section{ME Data Services (MEDS)}

Emily teamed up with Masana a former ICT consultant on the new MEDS venture which was setup in the third quarter of 2016. Emily had been running a boutique financial services company for over 10 years. Emily, a chartered accountant, had spent most of her professional life in forensic accounting, auditing and assurance advisory work. Masana had experience in implementing information systems and ICT strategy consulting. Emily and Masana had set up MEDS to offer outsourced IT supported data capturing and related services. Emily and Masana had noticed a need for such services in several organisations that they had interacted with in their prior roles, which included working in the following sectors:

- Banking

- Insurance

- Government

- Telecommunications

They were aware that private and public sector organizations received data from a huge range of sources and in a wide variety of formats. Physically entering data was a labour intensive process, and companies spent valuable time and money capturing, managing and processing this data. These processes could often be significantly more efficient if outsourced. They also noted that globally, the BPO sector was estimated to grow at 6\% every year for the next 6 years (Cushman \& Wakefield LLP 2016) and they aimed to explore potential ways to take advantage of this trend.

\section{The Service Offering - Bespoke data capturing}

MEDS sought to delight its customers through bespoke data capturing and management services, bespoke being a term used in the tailoring industry to denote product that was highly customized to the individual. The range of services included:

\section{Business data capturing}

MEDS assisted clients in capturing structured and unstructured data with accuracy and timeliness. The following were available:

- $\quad$ Manual data capturing of business data and forms

- $\quad$ Barcode based data capture

\section{Large scale data capturing projects}

MEDS offered solutions for once-off data capturing projects where an organisation needed to capture large volumes of data acquired outside the normal course of their day-day operations, such as:

- $\quad$ Research related data

- $\quad$ Employee surveys

- $\quad$ Customer surveys

- $\quad$ Census data

- $\quad$ Election data

- Questionnaires 


\section{Data conversion}

MEDS offered scanning of documents (on-going and once off) for clients. The service was supported by the use of optical character recognition (“OCR”) software so the documents became searchable.

\section{Data analysis}

Depending on the client requirements, MEDS applied appropriate methods of data analysis that were determined by the data types and variables of interest. This was coupled with a systematic approach to data analysis that covered the locating, scoping, acquiring, testing and verification of data. Additionally MEDS employed statistical and / or logical techniques to compile data analysis reports.

\section{Data cleansing}

MEDS supported clients in ensuring that their data was trustworthy. The service involved detecting and correcting or deleting corrupt or inaccurate records from a record set or database. The actual process of data cleansing generally involved removing typographical errors or validating and correcting values against a known list of entities.

\section{Foundational Principles and Service Benefits}

The MEDS service offering was underpinned by the following principles:

- An appreciation of the importance of accurate data capturing to support the business processes and operational needs of an organisation.

- $\quad$ The use of leading technologies and software in conjunction with an experienced data capturing team.

- $\quad$ An understanding of client requirements that were assessed and agreed upon prior to the start of all engagements.

- $\quad$ A respect for the multilingual and multicultural landscape of South Africa, achieved through supporting a range of language capabilities (see Exhibit 2).

- $\quad$ Adherence to security and confidentiality procedures for all engagements.

Customers using MEDS services gained a multitude of benefits:

- $\quad$ Cost reduction. A reduction in administrative overheads and staff costs.

- $\quad$ Security. MEDS premises as well as the technology hardware and software had stringent security to ensure the security of customer documents and information.

- $\quad$ Space. Customers have reduced requirements for additional office space for filing rooms with cabinets full of paper based records.

- Data quality. MEDS followed rigorous quality assurance processes to ensure the integrity of the services offered (as it is often said "Garbage in-Garbage out").

- Avoiding distractions. MEDS customers were able to focus on their core business and respond easily to changes in their markets.

- $\quad$ Pricing. MEDS offered competitive pricing.

- $\quad$ Rapid response. MEDS staff were appropriately trained and qualified thus providing quick turnaround times. 


\section{The Business Situation}

The customer base was comprised mainly of South African based companies that outsourced data capturing and other related services to MEDS. However, the two entrepreneurs wanted to grow their business to attract global customers. They were considering branching out to the following locations: the United Kingdom, Australia, New Zealand, Europe and the United States. These locations had been identified as having advantages due to language, culture and existing trade relations with South Africa, coupled with expected sustained growth in the global BPO market. The UK and European markets, in particular, were positioned as potential growth areas for MEDS. These markets were characterized as (CBI, 2015):

- Increasingly open towards service outsourcing and offshoring as a way to reduce costs, access skilled labour and improve efficiency;

- Information Technology Outsourcing (ITO) was estimated to represent around $80 \%$ of the value of the European service outsourcing market;

- An increasing number of European companies and organisations were seen as adopting a multivendor outsourcing model. Smaller contracts and the multi-vendor model were growing in popularity as they mitigate risks and provide more flexibility to organisations.

- Smaller outsourcing contracts generally offered better opportunities for service providers in developing countries, as such providers often did not have the capacity for large outsourcing deals;

- Business Process Outsourcing (BPO) was estimated to represent around 20\% of the value of the European service outsourcing market.

MEDS had a team of four (4) permanent staff members and was looking to grow to a team of fifty (50) or more permanent staff members. MEDS aimed to empower women and run a $90 \%$ women employed business within the next 5 years. The MEDS team had an additional objective of attracting funding from the South African Department of Trade and Industry (DTI). The Government in South Africa had created and implemented the "Business Process Services" (BPS) incentive programme from January 2011 until 2014 with the goal of increasing investment in the country and additionally creating much needed work opportunities through offshoring activities. In light of South Africa's commitment to promote the country as a preferred location for the outsourcing of BPS, an implementation evaluation of the incentive programme was undertaken with a recommendation to continue it past the initial three-year duration.

The founders of MEDS had some burning questions to address to determine their next step and the direction the company should take in the short to medium term. They reviewed their situation from an internal and external perspective to inform their strategic direction options. The following sections on the external and internal considerations highlight some of the issues that they had been pondering on.

\section{External Considerations}

The external or contextual factors that could influence MEDS were considered using PEST (political, economic, socio-cultural and technological) analysis, a useful tool for understanding the realities within which the organisation operates. Used effectively, it could enable the organisation to compile appropriate plans to address the realities faced by the organisation (see Exhibit 3).

\section{Political Factors}

Political uncertainty: The International Monetary Fund (IMF) had highlighted in mid-2016 that political uncertainty in South Africa and concerns around governance matters continued to impact investor confidence. It also noted that the high levels of corruption in the country were inhibiting 
economic growth and damaging the trust that people had in the public sector. The country also undertook local government elections in which the ruling political party lost leadership of three large metropolitan cities to opposition parties which some say indicated a shift in the political landscape that could have implications for businesses? How might MEDS be affected by the turning political tide?

Funding: The South African government was well aware of the importance of developing the economy, creating employment and attracting foreign investment. They had thus set up various funding instruments and grants particularly aimed at small and medium enterprises. How could MEDS attract financial support for their growth strategy? How would their approach differ for government funding versus private investments or products available from the banking sector?

\section{Economic Factors}

Economic uncertainty: In May 2016 the then South African Finance Minister Pravin Gordhan announced that growth for 2016 was forecast at 0,9\% while Statistics SA reported that 15,000 jobs were lost in the formal sector in the first quarter of 2016. The South African Rand has also been challenged and was facing a battering against the US Dollar and British Pound; the Rand had however had showed signs of recovery in the latter half of the year. These were tough times for the economy. How could MEDS grow in such an environment?

Labour Market: The labour market in South Africa was regulated tightly, potentially impacting the company's ability to scale up or down quickly. This could lead to potential concerns where larger contracts, required the acquisition of staff, reached an end. How should MEDS gain flexibility in obtaining human resources considering the regulatory environment?

\section{Social Factors}

Developing Nation Challenges: South Africa remained a developing nation where a large portion of the population was categorised as poor, still facing historical challenges brought about by years of apartheid. The nation was highly focused on driving development and growth aimed at benefiting the entire population and overcoming poverty, illiteracy and unemployment. South Africa had adopted the National Development Plan (NDP) as a strategy for achieving socio-economic development. The NDP argued that ICT's may be used to tackle some of the country's social problems. Considering this context, how could MEDS position its service offering and structure its business to contribute to the community within which it operated? Should MEDS consider a triple bottom-line (see Exhibit 4) approach on how they conduct their business?

\section{Technological Factors}

ICT Environment: South Africa's ICT sector was growing and increasingly becoming an important contributor to the country's GDP. The ICT sector comprised of hardware, software, networking and related professional products and services. Global ICT companies ran operations in South Africa and the industry was considered to be an innovative leader in areas such as electronic banking. The ICT infrastructure had also experienced several changes. For instance, the under-sea cables such as the African Coast to Europe (ACE) and Eastern African Submarine System would rapidly increase the rates of data transfer to the global internet. Internally, the nation had a network comprised of fixed line, wireless and satellite communications. How could MEDS make potential global customers aware of continuous improvements being made in the country’s infrastructure? 
Growth of Mobile Market: A key characteristic of South Africa's ICT landscape included the rapid growth of the mobile telephony market. Indeed, there were more active SIM cards than the population of the country. Unfortunately, broadband access still remained relatively low and the costs of communication remained relatively high as compared to other developing nations, particularly in Asia. Approximately two thirds of the population had no access to the internet, suggesting a pressing need to address the persistent digital divide. What, if any, implications would this have for MEDS strategy as it looked to the future?

Disruptive Technologies: Gartner Inc. (NYSE: IT) (2016a) predicted that the rise of the machine could lead to obsolescence of offshoring for competitive advantage. They asserted that smart machines (inclusive of cognitive technologies) and algorithmic business models would challenge the notion that talent and humans were synonymous. Gartner Inc. (NYSE: IT) argued that human resources arbitrage will cede to hyperautomation arbitrage. Thus sourcing and supply chain managers would need to consider new approaches or they could fail to keep up with the competition. Additionally Capgemini (2015) reported that Robotic Process Automation (RPA) was rising and affecting Back Office and BPO services providers. They believed that "the ever-increasing sophistication, and consequent application, of RPA in the BPO domain is now swelling a virtual workforce as never before. The new wave of RPA can so dramatically increase the capacity to do work, in such a cost effective manner and with such a heightened level of accuracy, that labour intensive back office functions are being 'picked up' by rapidly advancing RPA technologies." What might be the consequences of such disruptive technologies for the MEDS team and its strategic direction, much of which was driven by the current advantage that humans held over machines in dealing with messy data?

\section{Internal Constraints}

The internal organisation factors at play within MEDS were analysed using the "Golden Triangle”, a framework that examined People, Process and Technology perspectives (see Exhibit 5).

\section{Human Resource Factors}

Training women for empowerment: MEDS had taken a conscious decision to make their business a "pro-women" environment. They believed that in the context of South Africa's history, developing and growing women would have a powerful impact on its communities. What kind of training should MEDS provide for entry level women vs. experienced staff? How would the training impact on the services provided and how could they track this impact?

Recruitment: MEDS required a flexible and fast recruitment process so that if they signed up a client the engagement project could start within a week of obtaining the contract. MEDS had only four (4) full-time permanent employees and could not afford to keep more than this number on a full-time basis unless they signed up new clients and improved revenue. This posed a challenge. For instance if MEDS was to sign one of the large financial institutions as a client, where should they recruit from? Should they target university students, should they set up a learnership programme that continuously produced a specified number of graduates per year?

\section{Organisation and Process Factors}

Business stage: The MEDs founders were well aware of perils of being in a start-up business and had seen the harrowing statistics around start-up failure (See Exhibit 6). They wanted a strategy that would enable them to overcome the first five (5) years of being in business. What should their priorities be? 
Expansion strategy: How should MEDS market to potential international customers? Should MEDS offer data capturing in languages other than English and the ten (10) other official languages of South Africa? What implications would this decision have for their staffing approach, quality assurance processes and the training requirements?

Additional services such as digital mail room: A digital mailroom provided services that were aimed at reducing the handling and management of paper. It would typically involve managing all inbound paper, faxes, emails and even web communications for a client. Some of MEDS competitors already offered this service. Should MEDS consider this? What would this mean for their processes and technology requirements? How might MEDS use technology to track, identify, organise, categorise and capture the received information? How could they test the feasibility and impact of such a service?

Credibility: MEDS was the "new kid on the BPO block". In consequence, they needed to establish credibility with their potential customers, particularly international clients. MEDS often dealt with confidential customer information. How could they build an online brand that remained credible for their current customers while also offering credibility to potential customers that might be on a different continent?

\section{Internal Technology Factors}

Technology investment: There were a range of technology solutions available for data capturing services. These went by acronyms that included OMR, OCR and ICR (see Exhibit 7). Which options should MEDS invest in, taking into account their vision for growth over the next five (5) years? Also, since technological innovations moved rapidly - how should they accommodate this pace of change?

\section{The Decision}

Masana and Emily had several issues to consider before making their next move. They needed to take into account the various internal and external constraints to map out a strategy for their new business in the fast paced BPO domain. The list of questions to be resolved was quite large, and included:

- $\quad$ Which international markets should MEDS target?

- $\quad$ Should MEDS change their current service offering?

- What should their recruitment strategy focus on?

- What aspects should their human resource development and training emphasize for their business needs?

- What technologies should the company invest in?

- $\quad$ How should MEDS prepare for potential disruptive innovations in the BPO sector?

- How may the company attract external funding?

- How may MEDS consider the "triple bottom-line" and contribute to their communities?

- How should MEDS build credibility with clients that are often in different geographical locations?

\section{References}

BPESA (2015) (Business Process Enabling South Africa). South Africa's BPO Proposition. Retrieved from http://www.bpesa.org.za/wp-content/uploads/2017/06/South-Africa-Value-Proposition.pdf 
Capgemini (2015). BPO's next wave of Robotic Process Automation. Retrieved from https://www.capgemini.com/resources/bpos-next-wave-of-robotic-process-automation

CBI (2015). CBI Trade Statistics: Outsourcing in Europe. CBI- The Centre for the Promotion of Imports from developing countries. Retrieved from https://www.cbi.eu/sites/default/files/market_information/researches/trade-statistics-europeoutsourcing-2015 0.pdf

Cushman \& Wakefield LLP ((2016). Where in the world? Business process outsourcing and shared service location index 2016 report. Retrieved from http://www.qbusiness.pl/uploads/Raporty/cwbpo2016.pdf

DTI (2015) (The Department of Trade and Industry). Financial Assistance Incentives. Retrieved from www.thedti.gov.za/financial_assistance/financial_assistance.jsp

Gartner Inc. (NYSE: IT) (2016a). Predicts 2016: The Rise of the Machine Leads to Obsolescence of Offshoring for Competitive Advantage. Retrieved from https://www.gartner.com/doc/3175128/predicts--rise-machine-leads

Gartner Inc. (NYSE: IT) (2016b). Evaluate Offshore/Nearshore Countries for Outsourcing, Shared Services and Captives Worldwide, 2016. Retrieved from https://www.gartner.com/doc/3231817/evaluate-offshorenearshore-countries-outsourcing-shared

Sharma, S. (2016). How digital disruption is a huge opportunity for BPO companies. Retrieved from https://www.linkedin.com/pulse/how-digital-disruption-huge-opportunity-bpo-companiessharma-cfa/

STATS-SA (2017a. (Statistics South Africa) Mid-year population estimates. Retrieved from http://www.statssa.gov.za/publications/P0302/P03022017.pdf

STATS-SA (2017b) (Statistics South Africa). Poverty Trends in South Africa: An examination of absolute poverty between 2006 and 2015. Retrieved from http://www.statssa.gov.za/publications/Report03-10-06/Report-03-10-062015.pdfhttp://www.statssa.gov.za/publications/Report-03-1006/Report-03-10-062015.pdf

STATS-SA (2017c) (Statistics South Africa). GDP Presentation. Retrieved from http://www.statssa.gov.za/publications/P0441/GDP_Presentation_Q2_2017.pdf

Yang, D.H., Kim, S., Nam, C. and Min, J.W., (2007). Developing a decision model for business process outsourcing. Computers \& Operations Research, 34(12), pp. 3769-3778. 


\section{Biography}

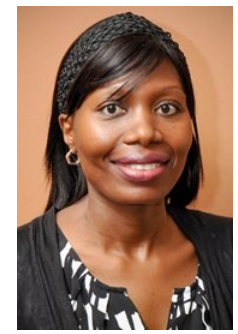

Dr. Tendani Mawela completed her PhD degree in Informatics at the University of Pretoria where she focused on the conceptualization of transformational government within e-government programmes of African countries. Tendani has experience in management consulting having worked on a variety of projects within the private and public sectors. She has also lectured at higher education institutions and published in journals and conferences on e-government. 


\section{Exhibit 1: South Africa Share of Nominal GDP Quarter 2 of 2017}

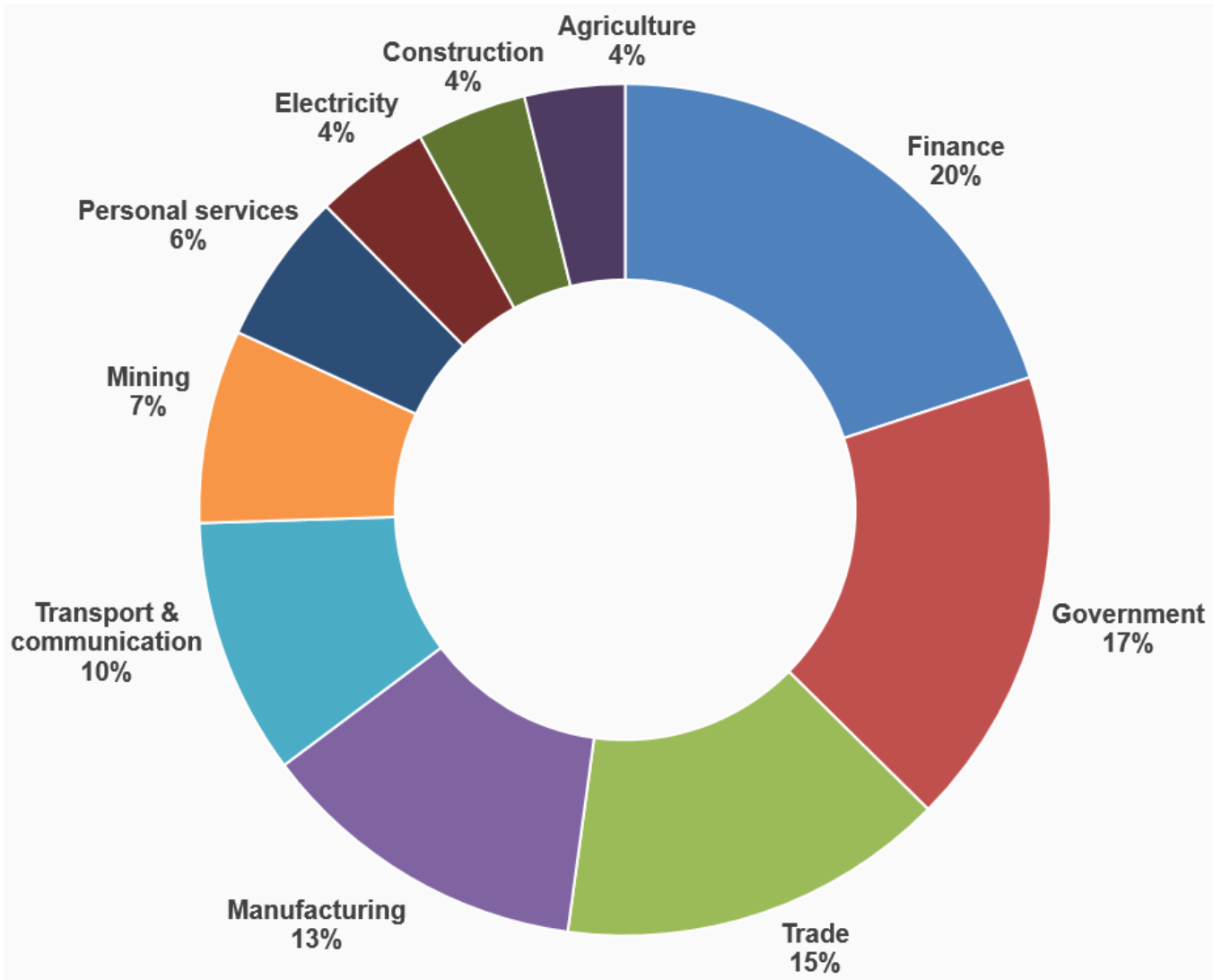

Source: Statistics South Africa (http://www.statssa.gov.za/?page_id=1859) 


\section{Exhibit 2: Language Statistics for South Africa}

\section{Percentage distribution of population by first language spoken}

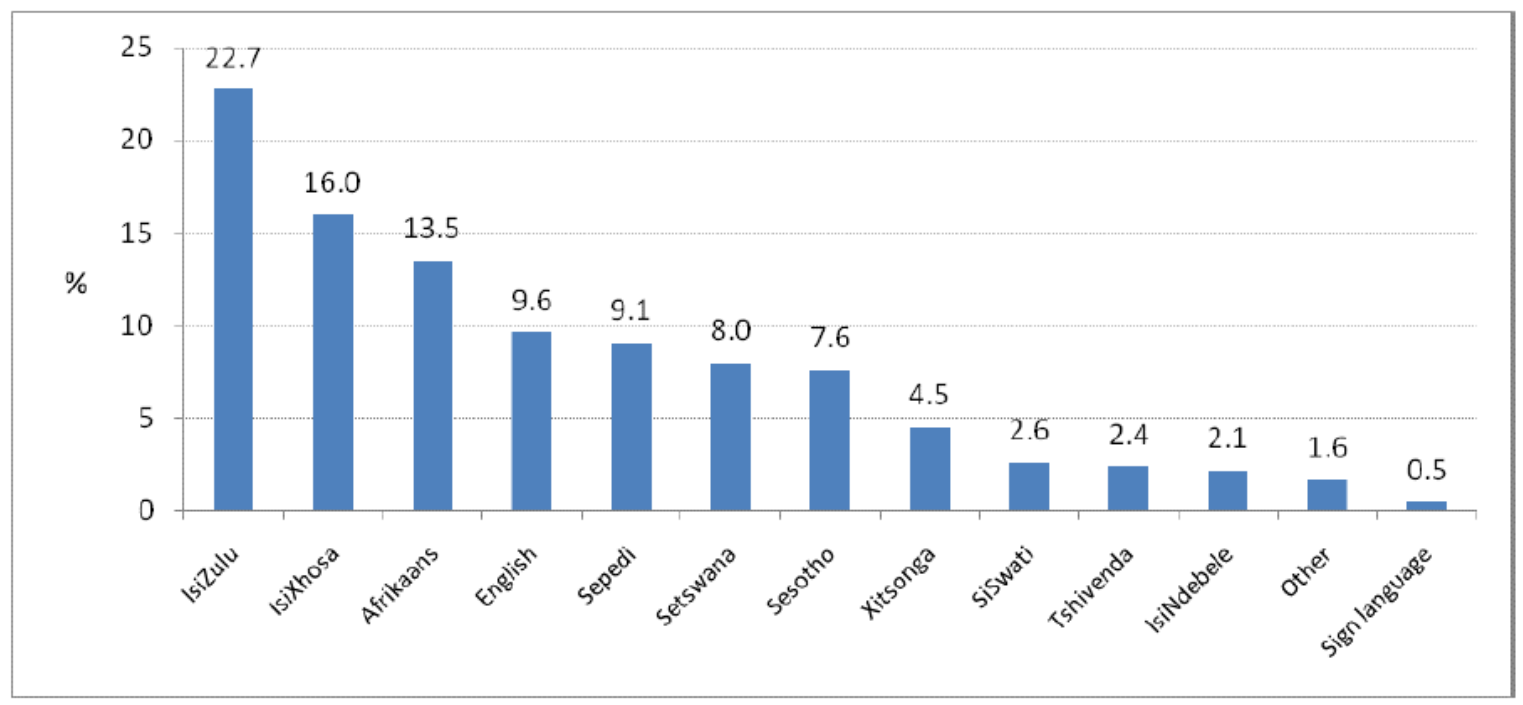

Source: Statistics South Africa- Census 2011 Report (http://www.statssa.gov.za/?page_id=1859) 


\section{Exhibit 3: PEST analysis factors}

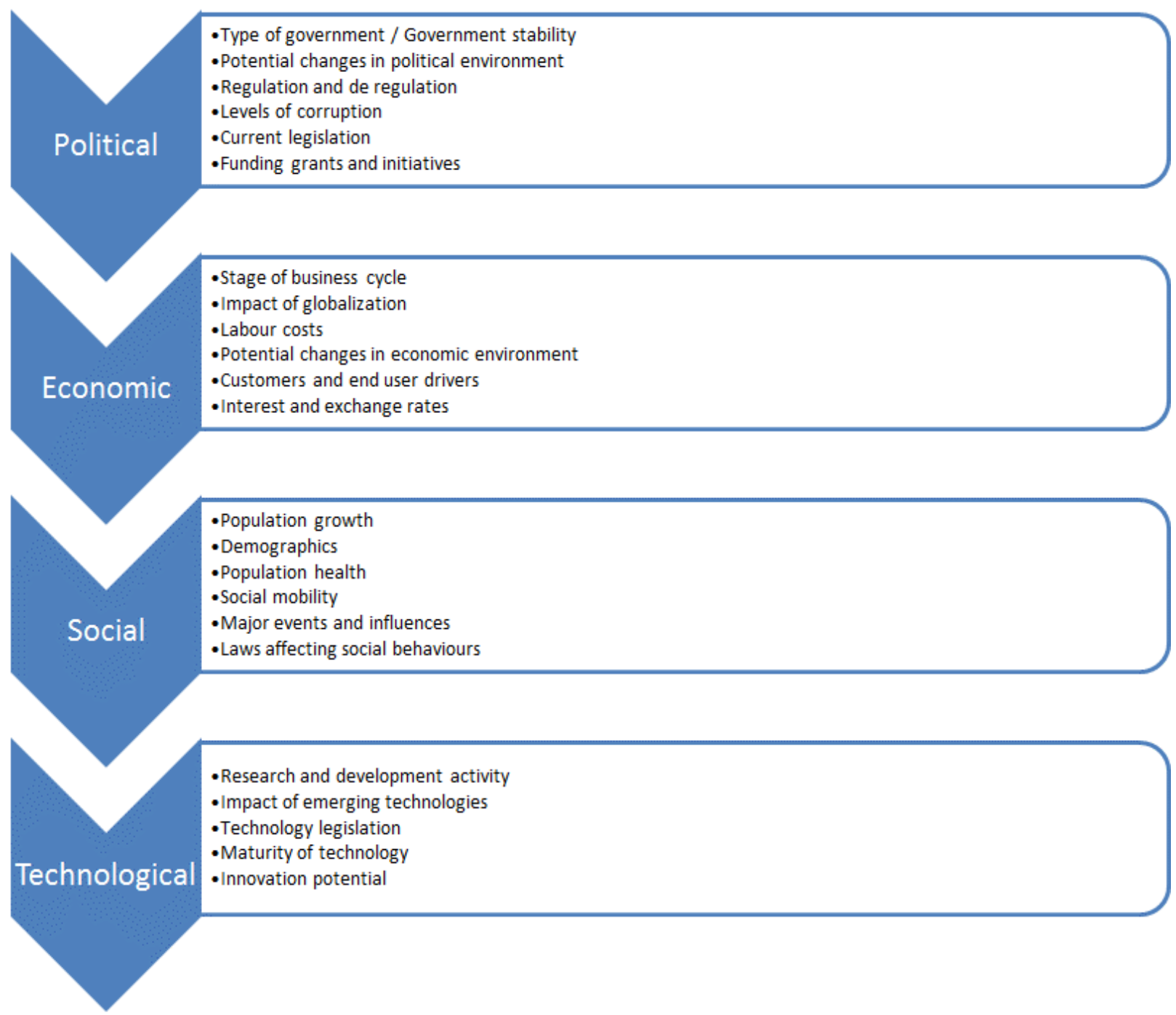

Source: Adapted by case writer from: http://pestleanalysis.com/pest-analysis/

\section{Exhibit 4: Triple bottom line approach}

\begin{tabular}{|l|l|l|}
\hline \multicolumn{3}{|c|}{ Triple Bottom-Line Principles } \\
\hline Economic Performance & Environmental Performance & \multicolumn{1}{c|}{ Social Performance } \\
\hline $\begin{array}{l}\text { Make profit in a sustainable } \\
\text { manner }\end{array}$ & $\begin{array}{l}\text { Helping and protecting the } \\
\text { environment }\end{array}$ & Affect society positively \\
\hline Total shareholder return & Complinace to environmental rules & Diversity in the organisation \\
\hline Risk management & Emissions reductions & Equal opportunities and skills \\
\hline
\end{tabular}


MUMA CASE REVIEW

\begin{tabular}{|l|l|l|}
\hline & & enhancement for staff \\
\hline Margin improvement & Resource efficiency & Community outreach programmes \\
\hline
\end{tabular}

Source: Adapted by case writer from: http://www.ibrc.indiana.edu/ibr/2011/spring/article2.html 
AUTHORS

\section{Exhibit 5: Triangle for organisational change}

\section{People}
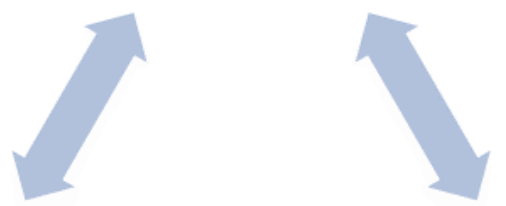

\section{Process}

\section{Technology}

Source: Adapted by case writer from: https://analyze.co.za/people-process-technology-importantconsider-3/ 


\section{Exhibit 6: Startup Failure Data}

\section{Start-up business failure rate by industry}

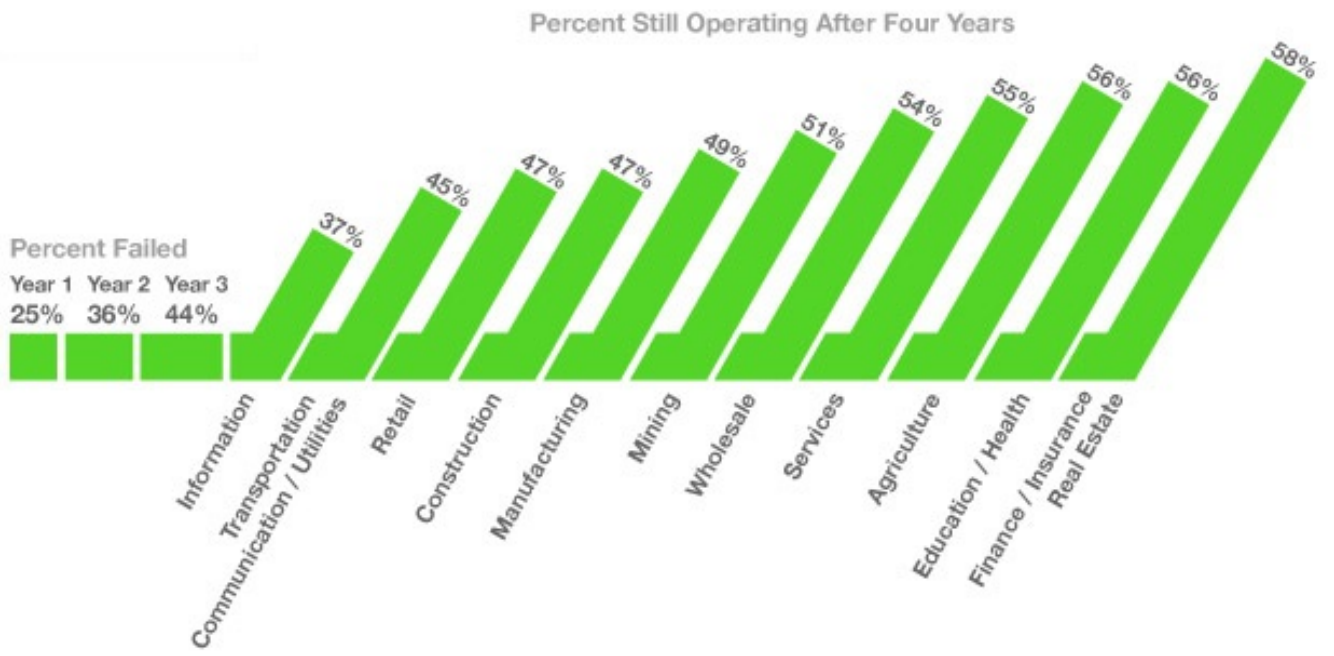

Source: www.statisticbrain.com

\section{Typical causes of start-up business failure}

\begin{tabular}{|c|c|c|}
\hline \multicolumn{3}{|c|}{ Typical Causes of Business Failure } \\
\hline \multirow[t]{7}{*}{1} & \multirow[t]{7}{*}{ Incompetence } & Emotional Pricing \\
\hline & & Living too high for the business \\
\hline & & Non-payment of taxes \\
\hline & & No knowledge of pricing \\
\hline & & Lack of planning \\
\hline & & No knowledge of financing \\
\hline & & No experience in record-keeping \\
\hline \multirow[t]{3}{*}{2} & \multirow{3}{*}{$\begin{array}{l}\text { Unbalanced Experience or Lack } \\
\text { of Managerial Experience }\end{array}$} & Poor credit granting practices \\
\hline & & Expansion too rapid \\
\hline & & Inadequate inventory \\
\hline \multirow[t]{2}{*}{3} & \multirow{2}{*}{$\begin{array}{l}\text { Lack of Experiences in line of } \\
\text { goods or services }\end{array}$} & Carry inadequate inventory \\
\hline & & No knowledge of suppliers \\
\hline
\end{tabular}




\begin{tabular}{|l|l|l|}
\hline & & Wasted advertising budget \\
\hline 4 & Neglect, fraud, disaster & Fraudulent or neglectful actions \\
\hline
\end{tabular}

Source: Adapted by case writer from www.statisticbrain.com 


\section{Exhibit 7: Data Capturing Software}

\begin{tabular}{|c|c|c|c|}
\hline & OCR & ICR & OMR \\
\hline \multirow{3}{*}{ Description } & Optical Character Reader & $\begin{array}{l}\text { Intelligent Character } \\
\text { Recognition }\end{array}$ & Optical Mark Reader \\
\hline & \multirow{2}{*}{$\begin{array}{l}\text { Gives scanning and imaging } \\
\text { systems the ability to turn } \\
\text { images of machine printed } \\
\text { characters into machine } \\
\text { readable characters. }\end{array}$} & \multirow{2}{*}{$\begin{array}{l}\text { Gives scanning and imaging } \\
\text { systems the ability to turn } \\
\text { images of hand written } \\
\text { characters into machine } \\
\text { readable characters }\end{array}$} & $\begin{array}{l}\text { OMR is a data collection } \\
\text { technology that does not require a } \\
\text { recognition engine. }\end{array}$ \\
\hline & & & $\begin{array}{l}\text { OMR cannot recognize hand- } \\
\text { printed or machine-printed } \\
\text { characters. }\end{array}$ \\
\hline \multirow[t]{2}{*}{ Key features } & $\begin{array}{l}\text { Images of the machine printed } \\
\text { characters are extracted from a } \\
\text { bitmap of the scanned image. }\end{array}$ & $\begin{array}{l}\text { Images of the hand-written } \\
\text { characters are extracted from } \\
\text { a bitmap of the scanned } \\
\text { image. }\end{array}$ & $\begin{array}{l}\text { An OMR works with a } \\
\text { specialized document and } \\
\text { contains timing tracks along one } \\
\text { edge of the form to indicate } \\
\text { scanner where to read for marks } \\
\text { which look like black boxes on } \\
\text { the top or bottom of a form. }\end{array}$ \\
\hline & $\begin{array}{l}\text { OCR is less accurate than } \\
\text { OMR but more accurate than } \\
\text { ICR }\end{array}$ & $\begin{array}{l}\text { ICR will require editing to } \\
\text { achieve high data coverage. }\end{array}$ & $\begin{array}{l}\text { The cut of the form is very } \\
\text { precise and the bubbles on a form } \\
\text { must be located in the same } \\
\text { location on every form. }\end{array}$ \\
\hline \multirow{3}{*}{ Advantages } & $\begin{array}{l}\text { OCR recognize machine- } \\
\text { printed or characters. }\end{array}$ & $\begin{array}{l}\text { ICR recognize hand-printed } \\
\text { characters. }\end{array}$ & \multirow{3}{*}{$\begin{array}{l}\text { Designed properly, OMR has } \\
\text { more accuracy than OCR. }\end{array}$} \\
\hline & $\begin{array}{l}\text { Scanning and recognition } \\
\text { allows efficient management } \\
\text { and planning for the rest of the } \\
\text { processing workload }\end{array}$ & $\begin{array}{l}\text { Scanning and recognition } \\
\text { allows efficient management } \\
\text { and planning for the rest of } \\
\text { the processing workload }\end{array}$ & \\
\hline & $\begin{array}{l}\text { Quick retrieval for editing and } \\
\text { reprocessing }\end{array}$ & $\begin{array}{l}\text { Quick retrieval for editing } \\
\text { and reprocessing }\end{array}$ & \\
\hline Disadvantages & Technology is costly & $\begin{array}{l}\text { Additional workload to data } \\
\text { collectors -ICR has severe } \\
\text { limitations when it comes to } \\
\text { human handwriting }\end{array}$ & $\begin{array}{l}\text { Does not recognise handprint or } \\
\text { machine print }\end{array}$ \\
\hline
\end{tabular}

Source: Adapted by case writer from :

https://unstats.un.org/unsd/demographic/sources/census/wphc/dataCapture/docs/Data-Capture_ch06ABS.pdf 